\title{
Color Blind: Shedding Light on the Mental Health of LGBTQ People of Color
}

Kristan Scott, MD, Vincent C. Smith, MD, MPH

The National Perinatal Association (NPA) is an interdisciplinary organization that strives to be a leading voice for perinatal care in the United States. Our diverse membership is comprised of healthcare providers, parents \& caregivers, educators, and service providers, all driven by their desire to give voice to and support babies and families at risk across the country.

Members of the NPA write a regular peer-reviewed column in Neonatology Today.

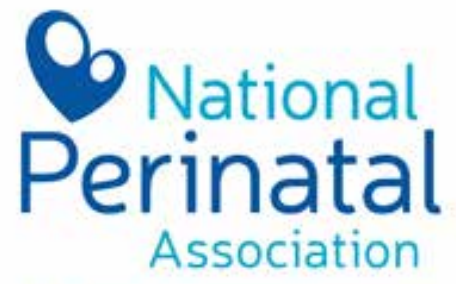

Educate. Advocate. Integrate.

"Their full support including around mental health issues - can make a huge difference for families. This is especially true for communities of color and LGBTQ (Lesbian, Gay, Bisexual, Transgender, Questioning/ Queer)-headed families."

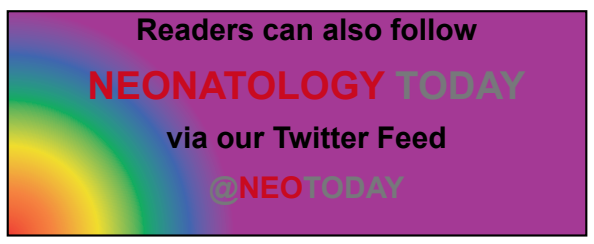

It is a frightening, isolating moment to be a new parent. And those supporting new parents right now - from medical providers and social workers to home visitors -- are critical front-line workers. Their full support - including around mental health issues can make a huge difference for families. This is especially true for communities of color and LGBTQ (Lesbian, Gay, Bisexual, Transgender, Questioning/Queer)-headed families.

\section{"With the rise of the Black Lives Matter movement} \section{and threats against} transgender employment rights and health protections, 2020 has been marked by significant social distress for communities of color and the LGBTQ community."

With the rise of the Black Lives Matter movement and threats against transgender employment rights and health protections, 2020 has been marked by significant social distress for communities of color and the LGBTQ community. Unfortunately, it is now well known that among the many consequences of social oppression, there are significant negative effects on the mental health of the oppressed populations. As healthcare providers in a time when more LGBTQ-identifying youth are entering pediatric practices, and the traditional American family structure is changing with an increase in LGBTQ-headed families, we must reflect on the health of this population, especially as it intersects with communities of color. As neonatal providers, it is vital that we also be aware these families will be carrying additional stresses, magnifying the already taxing experience of the NICU. This can lead to some skepticism related to medical practice and some heightened sensitivity to mistreatment.

According to the National Institute of Mental Health (NIMH), mental illnesses are common, with nearly one in five adults in America living with a serious mental illness. An estimated 17.3 million adults in the United States had at least one major depressive episode. An estimated $31.1 \%$ of adults will experience an anxiety disorder at some time in their lives. Notably, LGBTQ people are more than twice as likely to face a mental health problem in their lifetime compared to their heterosexual counterparts(1)suicide and substance misuse in lesbian, gay and bisexual (LGB. More strikingly, LGBTQ youth are over two times as likely to attempt suicide than their straight peers(2). The majority of mental illness develops by a person's mid-20s, which can ultimately have significant implications in areas such as work productivity in adulthood. $(3,4)$ Unfortunately, studies suggest that there is a significantly higher prevalence of mental health issues such as depression, anxiety, eating disorders, self-injury, and suicidality among LGBTQ college and graduate students, who are in this aforementioned age range. $(5,6)$ a mobile survey of randomly selected students $(\mathrm{N}=65,213$ at 71 U.S. campuses, including 1,237 gender minority [GM] students The data for mental health prevalence among racial minority populations varies; however, some studies suggest a significant burden of mental health problems among racial/ethnic minority students in addition to limited use of mental health services. $(7,8)$

The disproportionate presence of mental health problems for the LGBTQ community and communities of color is explained by the theory of minority stress. (9) It outlines how the stigma, prejudice and discrimination associated with a person's minority status (i.e., race, sexuality, gender) creates a negative social environment that results in mental health problems. Major discriminatory events like observing or experiencing differential treatment by medical providers that often go unmentioned to staff are certainly contributors to minority stress. Furthermore, microaggressions like providing inadvertently exclusionary handouts that say "mother" and "father" to a same-sex couple in the NICU certainly add to this stress. (10)

Intersectionality describes how social identities and social inequality based on race and sexual orientation are interdependent, not mutually exclusive. (11) As such, the way in which LGBTQ people of color experience the world is unique as they hold multiple identities of marginalization. For instance, LGBTQ people of color may both experience racism within the LGBTQ community and homophobia within their respective racial/ethnic minority communities. The end result is that many of these 
families don't feel welcomed or included by either the racial/ethnic minority or LGBTQ community. Recognizing the compounding effect of the multiple minority stressors, the prevalence of mental health problems in LGBTQ communities of culture may not be captured by studies that investigate the association of mental health with race and sexuality independently.

LGBTQ people of color represent an underserved and underresearched population, especially in the area of mental health. Considering the potential consequences of the intersectionality of race and LGBTQ status, the mental health prevalence of this population may not mirror that of the larger population. One online survey of 200 participants suggests an additive effect of multiple forms of discrimination on the mental health of LGBTQ people of color. (12)sexual orientation, and gender identity has been linked to many negative psychological and physical health outcomes in previous research, including increased suicidal ideation. Two hundred lesbian, gay, bisexual, transgender, and queer (LGBTQ However, few studies have investigated this issue or had a large enough sample size to elucidate significance.

As healthcare providers, we must investigate the etiologies and consequences of this inequity in the burden of mental health for the LGBTQ community of color and develop interventions to mitigate the effects of this disparity within our practices and ultimately within our health care system. Furthermore, as neonatal providers, we must recognize the burden of mental health issues impacting our families from LGBTQ communities of color and be proactive about assessing needs and providing essential support.

\section{References:}

1. Semlyen J, King M, Varney J, Hagger-Johnson G. Sexual orientation and symptoms of common mental disorder or low wellbeing: Combined meta-analysis of 12 UK population health surveys. BMC Psychiatry. 2016;16(1):1-9. doi:10.1186/s12888-016-0767-z

2. Goldbach JT, Rhoades $H$, Green $D$, Fulginiti A, Marshal MP. Is There a Need for LGBT-Specific Suicide Crisis Services? Crisis. 2019;40(3):203-208. doi:10.1027/0227-5910/ a000542

3. Kessler RC, Amminger GP, Aguilar-Gaxiola S, Alonso J, Lee $S$, Ustün TB. Age of onset of mental disorders: a review of recent literature. Curr Opin Psychiatry. 2007;20(4):359-364. doi:10.1097/YCO.0b013e32816ebc8c

4. Wang PS, Simon GE, Avorn J, Mcculloch J, Petukhova MZ, Kessler RC. and Care Management for Depressed Workers and Impact on Clinical. Jama. 2007;298(12):1401-1411. doi:10.1001/jama.298.12.1401

5. Lipson SK, Raifman J, Abelson S, Reisner SL. Gender Minority Mental Health in the U.S.: Results of a National Survey on College Campuses. Am J Prev Med. 2019;57(3):293301. doi:10.1016/j.amepre.2019.04.025

6. Horwitz AG, Berona J, Busby DR, et al. Variation in Suicide Risk among Subgroups of Sexual and Gender Minority College Students. Suicide Life-Threatening Behav. Published online 2020. doi:10.1111/sltb.12637

7. Lipson SK, Kern A, Eisenberg D, Breland-Noble AM. Mental Health Disparities Among College Students of Color. J Adolesc Heal. 2018;63(3):348-356. doi:10.1016/j.jadohealth.2018.04.014

8. Busby DR, Horwitz AG, Zheng $K$, et al. Suicide risk among gender and sexual minority college students: The roles of victimization, discrimination, connectedness, and identity affirmation. J Psychiatr Res. 2020;121(July 2019):182-188. doi:10.1016/j.jpsychires. 2019.11.013

9. Meyer IH. Prejudice, social stress, and mental health in lesbian, gay, and bisexual populations: conceptual issues and research evidence. Psychol Bull. 2003;129(5):674-697. doi:10.1037/0033-2909.129.5.674
10. Smith V, Litt J, Wylie M. Further Insights and Suggestions to Support the Lesbian, Gay, Bisexual, Transgender, and Queer/Questioning (LGBTQ)-Headed Family in the NICU. Neonatol Today. 2019;14(11):38-40.

11. Crenshaw K. Mapping the Margins: Intersectionality, Identity Politics, and Violence against Women of Color. Stanford Law Rev. 1991;43(6):1241. doi:10.2307/1229039

12. Sutter M, Perrin PB. Discrimination, Mental Health, and Suicidal Ideation Among LGBTQ People of Color. J Couns Psychol. 2016;63(1):98-105. doi:10.1037/cou0000126

Conflict of Interest Disclosures: The other authors have no conflicts of interest to disclose.

Disclosure: The National Perinatal Association www.nationalperinatal.org is a 501c3 organization that provides education and advocacy around issues affecting the health of mothers, babies, and families.
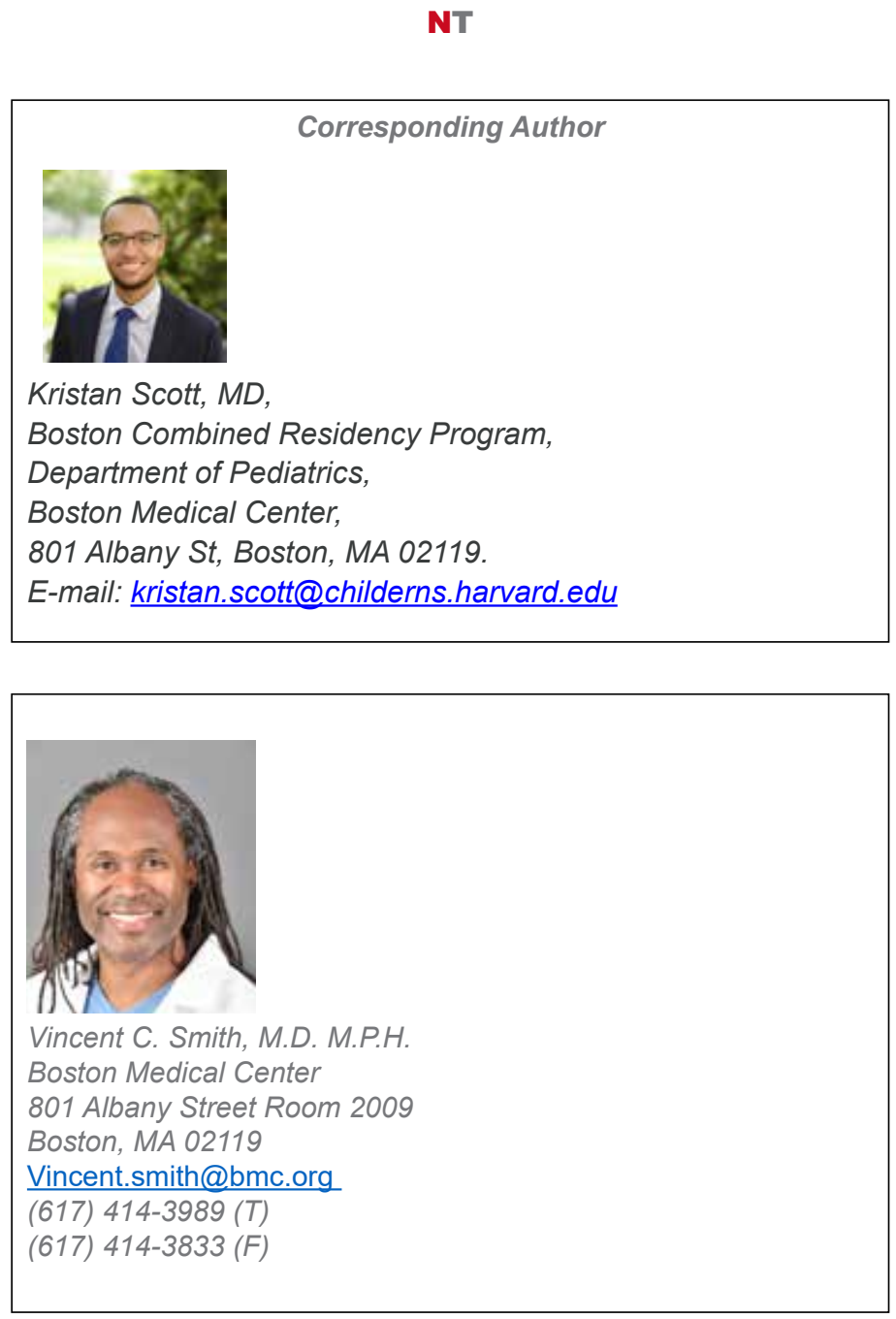